\title{
Cost Benefit Analysis to select clean energy solutions in dairy farm milk collection
}

\section{posts in Azores.}

\author{
A. Rodrigues ${ }^{1 *}$, T. Dentinho ${ }^{1 *}$, C. Silva ${ }^{2 *}$, E. Azevedo ${ }^{3 *}$ \\ ${ }^{1}$ Gabinete de Gestão e Conservação da Natureza. \\ Departamento das Ciências Agrárias. University of Azores \\ Largo da Igreja, 9700 - 181 Terra-Chã, Terceira - Açores \\ Phone number: (+351) 295402 229, Fax number: (+351) 295402205 \\ E-mail: anarodriges@uac.pt, tomazdentinho@uac.pt \\ ${ }^{2}$ Instituto Superior Técnico, Technical University of Lisbon \\ MIT-Portugal Sustainable Energy Systems \\ Av. Rovisco Pais, 1. 1049-001 Lisboa \\ Phone number: (+351) 218417 000, Fax number: (+351) 218499242 \\ E-mail: carlosaugusto.santossilva@mitportugal.org \\ ${ }^{3}$ Centro de Estudos do Clima, Meteorologia e Mudanças Globais. University of Azores \\ E-mail:edubrito@uac.pt \\ * All authors contributed equally to this paper.
}

\begin{abstract}
.
The aim of this paper is to evaluate the possibility of implementation of alternative renewable energy microgeneration installations in dairy farm milk collection posts, from the technical, economical and environmental perspectives.

This work was performed through a dairy farm milk collection post energy audit, to perform energy profile characterization and demand requirements. Following that, a study of the weather conditions was done and the obtained data (through CLIMAAT and MacSIMAR projects) [11] was introduced in a renewable energy solutions calculator (HOMER). Moreover, a system design from the available portfolio of micro-generation devices was defined and a cost benefit analysis of the selected alternatives was done. In the end a comparison of the current implemented solution with alternative designs was performed.
\end{abstract}

Results show that from the analyzed solutions for this case, the set of PV $(20 \mathrm{Kw})$ and Wind $(3 \mathrm{KW})$ with no batteries is the best one, since it presents the least cost of energy, the smallest initial capital and the highest Net Present Cost. The sensitivity analysis derive that wind micro-turbines should be installed except if the solar radiation is on its maximum value and that in no case the use of batteries is an advantage for the system operation.

For systems requiring a certain degree of energy (in this case with an average of $350 \mathrm{~kW} /$ day), the implementation of micro generation systems, like the ones evaluated, will never be economically viable in terms of Total Economic Value, even with generous feed-in tariff schemes. It is preferable that the grid operator makes investments in renewable energy production. To improve the system energy performance, the options should be focused on energy efficiency measures.

\section{Key words}

Renewable, energy, cost-benefit, dairy farm.

\section{Introduction}

Azores economic and social welfare depends greatly on dairy farming and dairy farm milk collection posts, which means that there is a need to find ways in which these industries can operate sustainably.

Today dairy farms and dairy farm milk collection posts are huge energy consumers, for several operations as water heaters, milk coolers, vacuum pumps, lighting, etc. Dairy farm milk collection posts are considered as an example of a typical SME (small and medium sized enterprise) but the methods and operations used in this research could be applied to all the other SMEs concerning energy renewable potential sources implementation.

In the future fossil fuels will become depleted and other energy forms will be cheaper and better in terms of GHG (Green House Gas) emissions, being strictly necessary to become sustainable in energy uses. One possibility is to develop and implement sustainable energy systems to promote the use of distributed micro generation facilities. If it is not possible in some places to have large power plants, one may use sunlight, wind or other renewable energy sources to have small generation facilities, in order to reduce the total required electricity demand and consequently, reduce the energy supply needs.

Usually dairy farm milk collection posts lack the time, resources and knowledge to effectively address on-farm energy analysis towards improvements. In this work it is intended to make energy audits and cost benefit analysis of renewable sources implementation to evaluate the possibility to substitute or complement conventional energy sources and analyze also possible savings in energy 
consumption on typical dairy farm milk collection posts of Terceira Island in Azores.

Installation of micro-generation equipments is technically available and mature, but economically depends largely on the incentives, like special tariffs for renewable production. These incentives are essential to allow a large number of users, but it is not sustainable on the long-term scenario. Nevertheless, not even with tax incentives people have changed for renewable sources, being clear that it is necessary to define other drivers for it.

The idea is also to have sufficient data to explore alternative policy solutions, like incentives in terms of electricity prices, tax incentives and others in order to help the government of Azores to design policies to promote micro-generation installation, both from a technical, economical and social point of view.

\section{Literature Review}

\subsection{Milk prices reduction through energy management improvements}

Business, industry and government organizations have all been under economic and environmental pressures in the last years. Being economically competitive in the global marketplace and meeting increasing environmental standards to reduce air and water pollution are the major driving factors in most of the recent operational cost and capital cost investment decisions for all organizations. Energy management has been an important tool to help organizations to meet these critical objectives for their short term survival and long-term success and decrease carbon dioxide, $\mathrm{CO}_{2}$ emissions, being this the primary culprit in global warming [1].

Being faced with constant increase in fossil fuel prices, energy efficiency and the use of some form of renewable energy sources becomes crucial in an every day industrial process. So, in dairy farm milk collection posts for the same amount of milk we would use less energy which could be crucial in today's dairy market. This would lead to cheaper milk production and better competitiveness of dairy farmers in the Portuguese market, deriving economic benefits for the farmers (and milk industry) as well as ecological benefits [2].

\subsection{Solar energy}

One must invest capital in a solar energy system in order to reap the benefits of this alternative energy source. In addition to the cost of the initial capital investment, one is usually faced with additional periodic or random costs due to operation and maintenance. Provided that the solar system does its expected task in a reasonably reliable manner, and presuming that the conventional energy source is available and satisfactory, it is important to evaluate if it saves money compared to the conventional system.
Obviously, the cost of money, the cost of conventional fuel, and the cost and performance of the solar system are all important factors [1].

Currently, Photovoltaic (PV) technology is most competitive in isolated sites, away from the electric grid and requiring relatively small amounts of power, typically less than $10 \mathrm{kWp}$. In these off-grid applications, PV is frequently used in the charging of batteries, thus storing the electrical energy produced by the modules and providing the user with electrical energy on demand. The key competitive arena for PV in remote off-grid power applications is against electric grid extension; primary (disposable) batteries; or diesel, gasoline and thermoelectric generators. PV competes particularly well against grid extension for small loads, far from the utility grid [3].

\subsection{Wind energy}

Wind energy to generate electricity is most feasible at sites where wind velocities are consistently high and reasonably steady. Ideally these sites should be remote from densely populated areas, since noise generation, safety. On the other hand the generators must be close enough to a consumer, so the energy produced can be utilized without lengthy transmission [1].

Because the typical wind device cannot furnish energy to exactly match the demand, a storage system and a backup conventional energy source may be made a part of the total wind energy system [1].The storage system might be a set of batteries and the backup system might be electricity from a utility. In some cases the system may be designed to put electrical power into the utility grid whenever there is a surplus and to draw power from the utility grid whenever there is a deficiency of energy. Such a system must be synchronized with the utility system and this requires either rotational speed control or electronic frequency control such as might be furnished by a field-modulated generator. Economics favours the system that feeds surplus power into the utility grid over the system with storage, but the former does require reversible metering devices and a consenting utility [1].

\subsection{Renewable energy sources calculator}

The hourly model chosen, HOMER, is an optimisation model and sensitivity analysis tool for designing standalone electric power systems [4]. HOMER uses hourly simulations to optimise the design of hybrid power systems, being able to model combinations of wind turbines, photovoltaic panels, diesel generators and battery storage.

\subsection{Cost benefit analysis}

Cost Benefit Analysis (CBA) is a model of rationality that provides support for informed judgement and decision making by private and public entities [5]. In CBA, Benefits are defined as increases in human well-being; Costs are defined as reductions in human well-being; a project or 
policy to qualify on cost-benefit grounds, if its social benefits must exceed its social costs; "Society" is simply the sum of individuals [6].

Searching the literature there are not many Cost Benefit Analysis directly related to the adoption of renewable energies by farms or Dairy farm milk collection posts. However there are some studies concerning just the economic feasibility of particular type of distributed renewable energies. In an article concerning wind farms it is shown that, without accounting for external costs and benefits, the generation costs of an onshore wind farm are between 4.5 and $8.7 €$ cent $/ \mathrm{kWh}[7]$.

Nevertheless there are some studies that use multi-criteria analysis. One study argues that PV is better than grid expansion in rural areas of Catalonia based on environment and social criteria because owners and inhabitants are neutral to the two alternatives if they are provided with sufficient amount of electricity [8].

In another multi-criteria analysis it is indicate that smallscale schemes are the most social and environmental effective in terms of the multi-criteria ranking, despite large-scale schemes being more financially viable [9].

There seems to be a need to undertake appropriate CBA analysis on decentralised renewable energies in order to frame and justify the calibration of the financial incentives to promote what multicriteria analysis points out to be better.

\subsection{Future work to develop}

GHG (Green House gases) emissions must be separated into direct and indirect emissions. Direct emissions arise from sources such as enteric fermentation and manure management. Indirect emissions are caused by the use of electricity. It is important to recognise that there are opportunities to minimise indirect emissions through improvements in energy use efficiency in dairy farms, through several options, such as:

- $\quad$ Plate coolers and cooling towers to reduce heat load in milk;

- Variable-speed drives on milk pumps and vacuum pumps;

- Energy-efficient lighting;

- High coefficient of performance (COP) refrigeration systems [10].

Energy processes on dairy farm milk collection posts allow for improvements in several processes, since there is not much research developed in this field. Old and out to date family farms can not compete with the new market standards. With the energy prices rise, energy efficiency on a dairy farm milk collection posts becomes a major issue. One of the most important things is to familiarize this industry with the possibilities of energy efficiency methods and present them the economic benefits of a certain energy efficiency method. While dealing with energy efficiency on a dairy farm milk collection post it is important to determine all the major energy flows so they could be dismembered and studied closely. That way we could determine the energy potentials for each of the energy consumer on a Dairy farm milk collection post. By comparing the present situation with possible improvements we could calculate exact savings for each of the farm section [2].

\section{Methodology}

\subsection{Characterization of the dairy farms network}

Firstly a characterization of the dairy farms and dairy farm milk collection posts network at the Azorean Island Terceira was performed, in order to access the best case studies to select.

\subsection{Energy Audit}

Firstly, background information of the facility was registered, namely information regarding geographical and weather data, facility layout, products/services, operating hours including seasonal variations, number of employees and relevant results of previous energy initiatives.

Secondly, the scope of the energy audit was defined in clear and measurable terms - space(s), systems and/or process (es) to be audited and the used approach to conduct the audit was defined.

During the energy audit, it was performed an operational/technological review of the firm and the several processes. After this, it was collected information regarding the historical development and present situation of the firm, as construction year and renovation and/or extension year(s).

Then, energy consumption and costs were assessed, as total consumption, consumption by energy types and costs during the last 12 months (2009), namely electricity supply and fuel (diesel) supply, through analysis of electricity bills and diesel consume rates assessment. It was also determined the rate structure under which that electricity and diesel were billed.

$\mathrm{CO} 2$ equivalent emissions for Diesel and electricity consumption were also calculated. A value of $20 € /$ ton $\mathrm{CO} 2$ was considered.

\subsection{Renewable energy production viability analysis}

The considered renewable energy potentials depend on the dairy farm milk collection post size and geographical position solar and wind data (for solar systems and wind micro-generation devices solutions).

For the renewable energy study, we considered the inputs from global and diffuse solar radiation and wind, compiled for the year 2009, from CLIMAAT database [11]. These 
data was introduced in HOMER database in order to obtain an extrapolation over the next years and estimate the potential use of solar and/or wind as energy sources. Figure 1 and 2 show the annual monthly averages for sunlight and wind. From this graphics it is possible to observe that the radiation is sufficient to consider $\mathrm{PV}$, but the average wind speed is in average low (under $6 \mathrm{~ms}-1$ ).

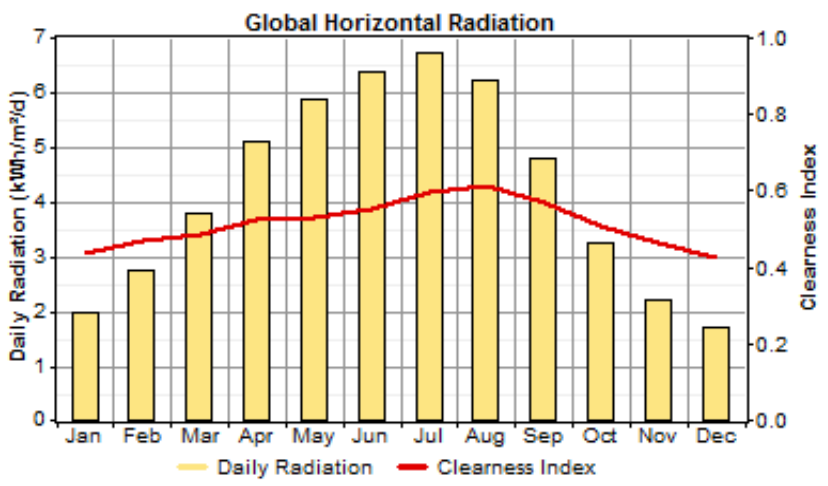

Figure 1 - Renewable resources potential (solar)

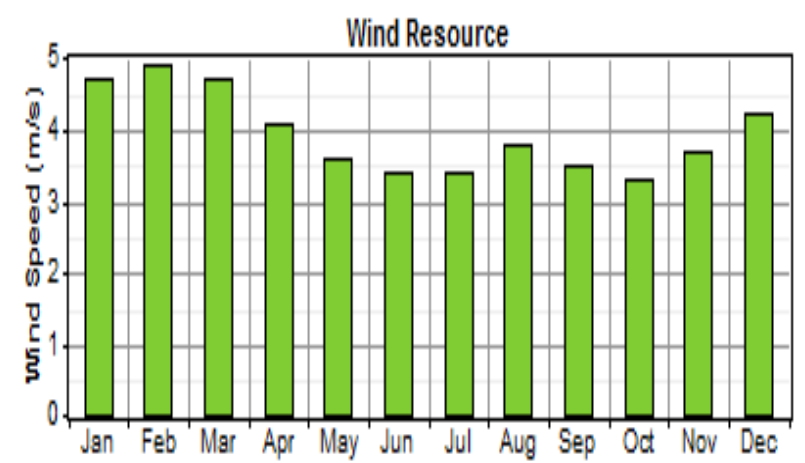

Figure 2 - Renewable resources potential (wind)

To evaluate the best set of renewable sources set of options, it is necessary also to consider the economic feasibility, i.e. to know in detail the Investment Costs (IC) and Operation and Maintenance Costs (OMC) for each technology (described in Table I), as well as the electricity tariffs (price, sellback) currently in use in Azores, described in Table II. We consider the costs currently in practice around the world [12] and for the electricity tariffs we consider the values currently used in Azores [13].

Table I - Renewable Resources Technology Costs

\begin{tabular}{|l|c|c|c|}
\hline Technology & $\mathrm{IC}(€ / \mathrm{kW})$ & OMC $(€ / \mathrm{kW}$.year $)$ & Lifetime (years) \\
\hline PV & 5800 & 58 & 25 \\
\hline Wind & 3500 & 175 & 15 \\
\hline Converter & 1250 & 100 & 10 \\
\hline Batteries & $170^{*}$ & 50 & 12 \\
\hline
\end{tabular}

* The IC of the battery is per $\mathrm{kWh}$

From the tables it is possible to see that the feed-in tariff is very high when compared to the maximum price at peak time, so there are also economic conditions to implement renewable electricity production.
Table II - Electricity prices in Azores

\begin{tabular}{|l|c|c|}
\hline Day period & $\begin{array}{c}\text { Price } \\
(€ / \mathrm{kWh})\end{array}$ & Sellback $(€ / \mathrm{kWh})^{*}$ \\
\hline Peak $(9-12,17-21)$ & 0,11 & 0,4 \\
\hline Full (7-9,12-17,21-24) & 0,08 & 0,4 \\
\hline Valley (2-6) & 0,05 & 0,4 \\
\hline Super Valley (0-2,6-7) & 0,045 & 0,4 \\
\hline
\end{tabular}

*This price considers a feed in tariff for renewable. This tariff is different for wind and solar PV, but here it is considered an average value.

\subsection{Cost Benefit Analysis}

For potential renewable energy source implementation, a cost benefit analysis for implementation of the technically proposed renewable energy sources was performed and potential savings were calculated.

\section{Results}

4.1. Characterization of the dairy farms and Dairy farm milk collection posts network at an Azorean Island Terceira

Terceira's Island has approximately $29 \mathrm{~km}$ length, 17,5 km width and $381,96 \mathrm{~km}^{2}$ area [13], with a population of around 55923 inhabitants [14].

UNICOL is a union of 21 cooperatives, being 20 of them from Terceira Island and one from Graciosa Island. It has 159 employees and the participated firms have 225 employees. If we consider the 1054 milk producers, we have a volume of 1438 direct employments, which makes it one of the firms with more social impact in Azores region.

UNICOL billed during 2008, 68 millions of Euros, being the seventh bigger firm of Azores, through the selling volume criteria analysis. UNICOL is the $13^{\text {th }}$ organization at the national level, being the $5^{\text {th }}$ bigger cooperative in the agriculture sector and the biggest cooperative in Azores.

UNICOL has at this time 22 Dairy farm milk collection posts, around 100 stationary milking bails and around 800 mobile milking plans in Terceira's Island. From the 100 stationary milking bails, 70 have electricity from the grid and electric power generator, and 30 have only an electric power generator with no connection to the grid. From the 800 mobile milking plans, 700 have a diesel engine and 30 have an electric power generator.

Dairy farms, in UNICOL's classification can be considered small (1-30 cows); medium (31-80 cows) and large size farms (81-150 cows). For a total of 900 milking plants, there are approximately 300 small, 500 medium and 100 large size dairy farms in Terceira's Island.

A typical Terceira's Island dairy farm milk collection post was chosen for this research, as being representative of all dairy farm milk collection posts, with small variants, not conditioning extrapolations for the other posts. 


\subsection{Energy audit results}

Basic observation was done by standard energy audit for the dairy farm milk collection post - UNICOL - Vinha Brava, Terceira, Azores.

Energy source: electricity. Nevertheless, an electric power generator is used in case any electricity failure occurs or for maintenance purposes, with an average use of $4 \mathrm{~L}$ diesel/month. This data was not considered in the calculations, since the electric power generator already exists in the facilities for maintenance purposes (Diesel cost: $0,9427 € / \mathrm{L}$ ) thus not affecting the analysis.

Demand charge and Rated power is $160 \mathrm{kVA}$, and contracted power is $74,40 \mathrm{KW}$, with contractual tariff TetraHourly rated.

During 2009, $144497 \mathrm{kWh}$ were used, with associated cost of $19377,48 €$, and a monthly average of $12041,42 \mathrm{kWh}$ with associated cost of $1614,79 €$.

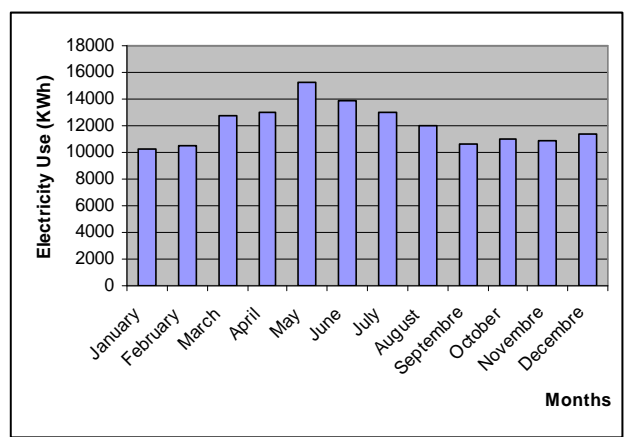

Fig. 3: Dairy farm milk collection post - UNICOL Electricity Consumption, during 2009.

For electricity, $144497 \mathrm{kWh} /$ year equivalent to 93634,06 $\mathrm{KgCO} 2 /$ year. Regarding diesel, $48 \mathrm{~L}$ diesel /year equivalent to $127,776 \mathrm{KgCO} 2 /$ year. In total: $93761,83 \mathrm{KgCO} 2 /$ year

\subsection{Renewable Energy Potential solutions}

In Figure 4, we present the typical consumption profile of a dairy farm milk collection post.

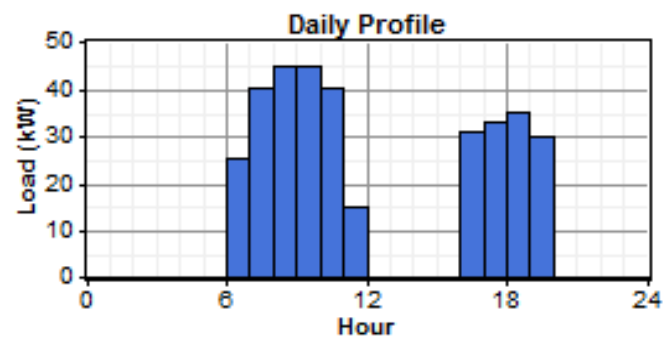

Figure 4 - Dairy farm milk collection post - UNICOL Consumption

As it can be seen, it has two active periods, one in the early morning and the other on the late afternoon that corresponds to the two daily milk collection periods.
The next step was to evaluate energy needed by the dairy farm milk collection post and the potential energy generated by solar and wind technologies, with the goal to determine the best solutions from the technical point of view. For the installed capacity optimization problem, we consider the following parameters:

- Solar PV (from 0 to $20 \mathrm{~kW}$ )

- Wind (from 0 to $15 \mathrm{~kW}$ )

- Batteries (from 0 to 20 batteries)

- Supply (variations up to $15 \%$ from day to day)

The best solutions are presented in Table III (considering an interest rate of 5\% and an NPC over 25 years).

Table III - Best technical solutions

\begin{tabular}{|l|c|c|c|c|}
\hline Solution & 1 & 2 & 3 & 4 \\
\hline PV $(\mathrm{kW})$ & 20 & 20 & 30 & 30 \\
\hline Wind $(\mathrm{kW})$ & 3 & 3 & 0 & 0 \\
\hline Batteries $(\#)$ & 5 & 0 & 0 & 5 \\
\hline Initial capital $(€)$ & 157500 & 151500 & 199000 & 205000 \\
\hline Net Present Cost $(€)$ & 502931 & 489977 & 501061 & 514216 \\
\hline Renewable Fraction $(\%)$ & 20 & 20 & 27 & 27 \\
\hline Cost of Energy $(€ / \mathrm{kWh})$ & 0,29 & 0,283 & 0,289 & 0,297 \\
\hline Emissions saved & 64245 & 64212 & 58218 & 58293 \\
\hline Electricity Grid $(\mathrm{kW})$ & 106787 & 106820 & 100260 & 100084 \\
\hline Electricity Sold $(\mathrm{kW})$ & 7182 & 7266 & 10000 & 9707 \\
\hline
\end{tabular}

From these solutions, solution 2 is the best one, since it presents the least cost of energy, the smallest initial capital and the highest Net Present Cost. In Figure 5 it is shown a week of operation of the system, in the beginning of the spring. As it can be seen, the solar PV devices production coincides with the first period of operation and the wind production occurs throughout the day, but contributes very little to the electricity needs.

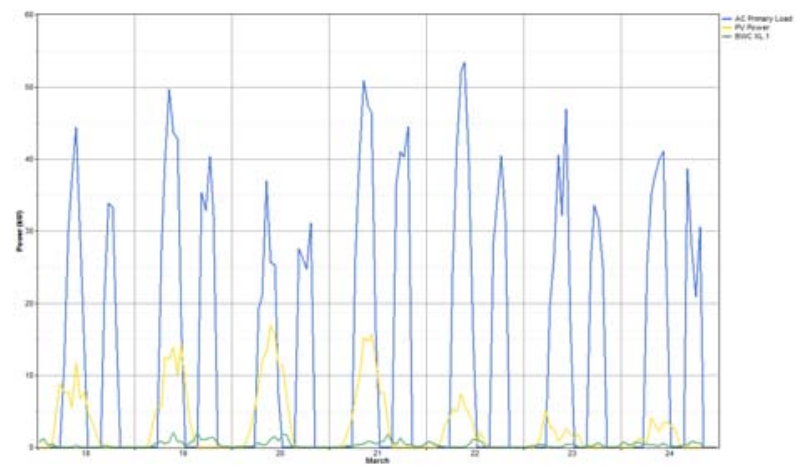

Figure 5 - Example of the system operation over a week

For the sensitivity analysis, we considered the following parameters:

- Sun radiation (3.5 instead of 4.25 average)

- Wind velocity (3 instead of 4 average)

The results for the sensitivity analysis are presented in Figure 6 . The results show that wind micro-turbines should be installed except if the solar radiation is on its maximum value. In no case the use of batteries is an advantage for the system operation - they only contribute to increase slightly the revenue, since they allow deferring the electricity purchasing to a period with lower electricity price. 


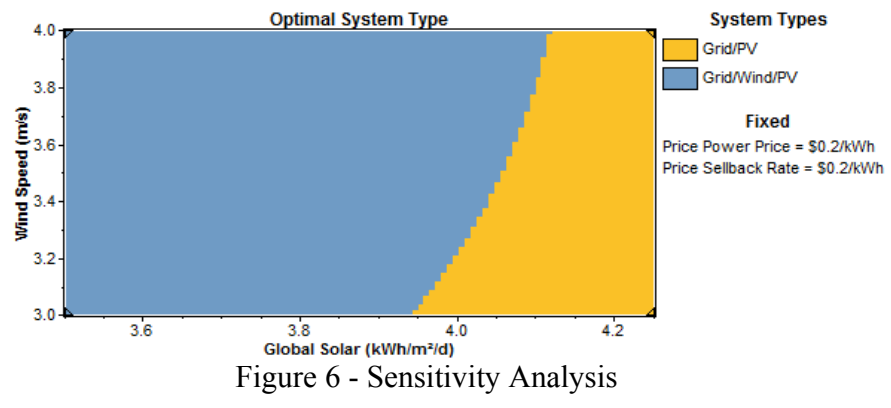

\subsection{Cost Benefit Analysis}

Even for an energy price of $0,4 € / \mathrm{kWh}$ and for value of emission of $20 € / \mathrm{Kg}$ the Net Present Value of the best technical solutions is very much negative (Table IV).

Table IV - Cost Benefit Analysis of the Best Technical Solutions

\begin{tabular}{|l|c|c|c|c|}
\hline & 1 & 2 & 3 & 4 \\
\hline Total Present Costs $€$ & 660431 & 641477 & 700061 & 719216 \\
\hline Total Present Benefits $€$ & 172104 & 171444 & 193013 & 195657 \\
\hline NetPresentValue(firm) $€$ & -488327 & -470033 & -507047 & -523558 \\
\hline NetValue Emissions $€$ & 18109 & 18100 & 16410 & 16432 \\
\hline NetPresentValue(society) $€$ & -470218 & -451933 & -490637 & -507127 \\
\hline
\end{tabular}

\section{Discussion}

The main ultimate contributions of this work is to conclude that there is no potential for renewable energy applications in Dairy Collecting Stations, and direct attention should be to improve the system energy performance, by focusing on energy efficiency measures, by reduction of fossil energy dependency and promotion of higher energy efficiency rates on dairy farm milk collection posts, thus decreasing costs, and improving benefits.

It is clear that this conclusion cannot be taken just with multi-criteria analysis or with a cost-effectiveness approach which is usually carried out in the literature on distributed renewable energy systems.

\section{Conclusion}

This study shows that for systems requiring a certain degree of energy (in this case with an average of $350 \mathrm{~kW} /$ day), the implementation of micro generation systems, like the ones evaluated in the previous sessions will never be economically viable, even with generous feed-in tariff schemes. In these cases, it is preferable that the grid operator himself makes the investments in the renewable production. To improve the system energy performance, the options should not be focused on the production of renewable electricity, but rather on energy efficiency measures. Thus, the future work will be to define potential energy saving opportunities regarding energy efficiency, with description of all proposed energy saving measures.

\section{Acknowledgements}

A. Rodrigues, T. Dentinho and C. Silva were supported by the project Net Energy Firms, Green Islands Project, MIT Portugal. CLIMAAT and MacSIMAR Projects were supported by FEDER - INTERREG_IIIB, Açores, Madeira and Canárias (MAC/2.3/A3) and by FEDER - MAC Transactional Cooperation (MAC/1/A089). The authors would like to express their sincere gratitude to the authorities of UNICOL for their support.

\section{References}

[1] W. Turner and S. Doty (2006) Energy Management Handbook. ISBN: 0-88173-542-6. Edition 6. Lilbum, pp. 2, 31, 58, 471, 472, 484, 486.

[2] T. Pukšec, G. Krajačić and N. Duić CO2 Reduction Potential in Croation Dairy Farming Sector. Department of Energy, Power Engineering and Environment. University of Zagreb, Zagreb, Croatia. 2007, pp. $1-3$ and 8.

[3] R. Adamson et all., Clean Energy Project Analysis. RETScreen ${ }^{\circledR}$ Engineering \& Cases Textbook. ISBN: 0-66239191-8. Third Edition. Retscreen Minister of Natural Resources Canada, (2004), pp. 93-113 and 171- 456.

[4] HOMER National Renewable Energy Laboratory, US Department of Energy http://www.homerenergy.com/

[5] European Commission, Directorate General Regional Policy (2008). Guide to Cost Benefit Analysis of investment projects Structural Funds.

[6] Pearce, D.; Atkinson, G.; and Mourato, S. (2006) - CostBenefit Analysis and the Environment. OECD.

[7] Blanco, M.I.(2009) - The economics of wind energy. Renewable and Sustainable Energy Reviews. Volume 13, Issues 6-7, August-September 2009, Pages 1372-1382.

[8] Russi, Daniela (2007) - Social Multi-Criteia Evaluation and renewable energy policies. Twi Case Studies. PhD Thesis of the Department of Economics and Economic History. Universitat Autónoma de Barcelona.

[9] Burton J. and Hubacek, K. (2007) - Is small beautiful? A multicriteria assessment of small-scale energy technology applications in local governments. Energy Policy. Volume 35, Issue 12, December 2007, Pages 6402-6412

[10]S. Birchall, C. Dillon, W. Dillon, R. Wrigley and W. Dillon, Effluent and Manure Management Database for the Australian Dairy Industry DAN 11806, CCG 12781. National Landcare Program. Australia (2008), pp 208 - 209.

[11] CLIMAAT Project - Center of Climate, Meteorology and Global Change of the University of the Azores. http://www.climaat.angra.uac.pt

[12] Economics of Owning and Operating DER Technologies. The California energy commission, http://www.energy.ca.gov.

[13] www.Azores.gov.pt

[14] http://www.ine.pt

\section{Appendix 1}

$\mathrm{CO}_{2}$ emission factor $\left(0,648 \mathrm{~kg} \mathrm{CO}_{2} / \mathrm{KWh}\right)$ used for electricity was the weighted mean of fuel oil $(89,5 \%)$, diesel $(2,9 \%)$, hydro $(0,2 \%)$ and wind power $(7,4 \%)$ generation appropriate for the study year (2009). Source: EDA (Azores Electricity Company)

The $\mathrm{CO}_{2}$ emission factor used for diesel was $2,662 \mathrm{Kg} \mathrm{CO}_{2} / \mathrm{L}$ diesel. Source: http://www.epa.gov/oms/climate/420f05001.htm 